\title{
A Review of an Electric Vehicle with two batteries facilitated to get charged in motion using wind energy
}

\author{
Swathi Polasa ${ }^{1}$, Rajkumar Sreepadapu ${ }^{2}$ \\ ${ }^{1}$ Senior Lecturer in Electrical and Electronics Engineering, Government Polytechnic - Nirmal-Telangana State, India \\ ${ }^{2}$ Head of Mechanical Engineering Section, Sanjay Gandhi Government Polytechnic - Adilabad-Telangana State, India
}

\begin{abstract}
Electrical vehicle (EV) is based on electric propulsion system. No internal combustion engine is used in it. All the power is based on electric power as the energy source. The main advantage is the high efficiency in power conversion through its offer system of electric motor. The operation, performance and efficiency of motor-driven electric vehicles are much better than engine-driven vehicles. The main drawback of Electric Vehicle is that it lacks the capability to run the vehicle for a long time due to insufficient energy storage in batteries. The energy storage capacity of the battery used in an electric vehicle is very low compared to conventional fuels used in modern automobiles. At the same time, electric vehicles are very environment friendly. Still, electric vehicles are falling behind in the automobile industries due to the problem of storage of energy. This paper proposes the concept of using dual battery system which is charged using wind energy when the vehicle is in motion or propelling. Charging the battery using wind energy may be done by using the energy of wind which is caused by the relative motion between the vehicle and the wind surrounding it. Wind turbines can be housed on the body structure of the vehicle to generate electricity in such a way that it must not create any additional drag force (rather than the existing drag force due to frontal area and skin friction) upon the vehicle. An aerodynamic analysis of the structure of the vehicle along with the flow pattern and wind turbine is presented in the paper. Optimum values of different design parameters and rated velocity of the vehicle are of prime concern. The idea behind the usage of two batteries (dual battery system) is to increase the reliability of the system and also to increase the run time. In future, we can charge the battery of electric vehicle by harvesting energy from other renewable energy sources like solar energy.
\end{abstract}

Keywords: Electric Vehicle, Wind Energy, Drag Reduction, Reliability, Energy storage system

\section{INTRODUCTION}

When a vehicle moves, it experiences two forms of wind resistance which are frictional drag and form drag. Due to the viscosity of air, frictional drag arises. Form drag arises due to variation of air pressure in the front and rear side of the vehicle [1]. As the vehicle moves forward, it leaves the air stream behind. A disturbance is created to the air flow when a vehicle moves through it. If stationary wind turbines are placed near the road, energy can be extracted from the wind stream generated due to the movement of the vehicle. Such a study had been carried out at the University of Arizona by a group of students and others. The Electric Vehicle with ducts in the front side is designed by Eolo Cars company in Columbia. For the proposed model, drag can be expected to be reduced by passing this air to the rear side (Low pressure side) of the vehicle. The air stream sliding over the body of the vehicle cannot enter the rear side due to vortex shedding [1]. The form drag can be reduced by some amount if air streams are allowed to flow in this rear side region, at the same time it may be possible to generate electricity using the kinetic energy of wind. Several studies had been carried out in this field, but none of them are proved to be scientific. Most of the design showed that the turbines are placed over the vehicle roof without considering the fact that it would impose an additional load on the vehicle. A design by Rory Handel and Maxx Bricklin showed that it has four tactically placed air intakes which would channel the air flow over the car's body towards the turbine. Such detailed design was not available. In this paper, the topic is dealt with by studying all the scientific facts and laws of energy conversion as mentioned in the research paper "Electric Vehicle with Charging Facility in Motion using Wind Energy"[11]. This paper also proposes two batteries with controller to increase the reliability and running time of the car based on paper Plug-In Hybrid Electric Vehicle with Dual Battery [17].

\section{EXPERIMENTAL METHODS OR METHODOLOGY}

2.1 Basic Theory: There are certain assumptions made. We assumed that the vehicle was moving in a calm and steady wind stream with zero wind velocity. If the vehicle is moving at a constant speed of $54 \mathrm{~km} / \mathrm{h}$ (i.e., $15 \mathrm{~m} / \mathrm{s}$ ), then we can think of a wind stream with speed $15 \mathrm{~m} / \mathrm{s}$ (minimum) flowing around the vehicle. A drag force which is opposite to the 


\section{International Advanced Research Journal in Science, Engineering and Technology}

Vol. 8, Issue 6, June 2021

DOI: $10.17148 /$ IARJSET.2021.86113

direction of the propulsion of the vehicle is caused by the wind. The energy requirements to move the vehicle forward at constant speed are to overcome the frictional force (rolling resistance of road) and to overcome wind resistance [1]. If the air stream generated by the interaction of the wind and vehicle is captured in such a way that additional drag at the direction of propulsion is not imposed, some of the energy can be recovered by placing the wind turbine and fed back to the battery. At the same time, it will help to increase the pressure at the back side (according to Bernoulii's equation, if velocity is reduced, pressure will be increased and velocity will be reduced at the back side of the turbine after energy extraction) which will reduce the drag force that existed before with the conventional design of the vehicle. So, vortex shedding will be lowered at the rear side. For this, modified design of a vehicle which provides air flow through the vehicle is required. Turbines must be placed in such a way that they do not create any additional drag on the vehicle. Positioning the turbines symmetrically can facilitate cancelation of the thrust acting on the turbines.

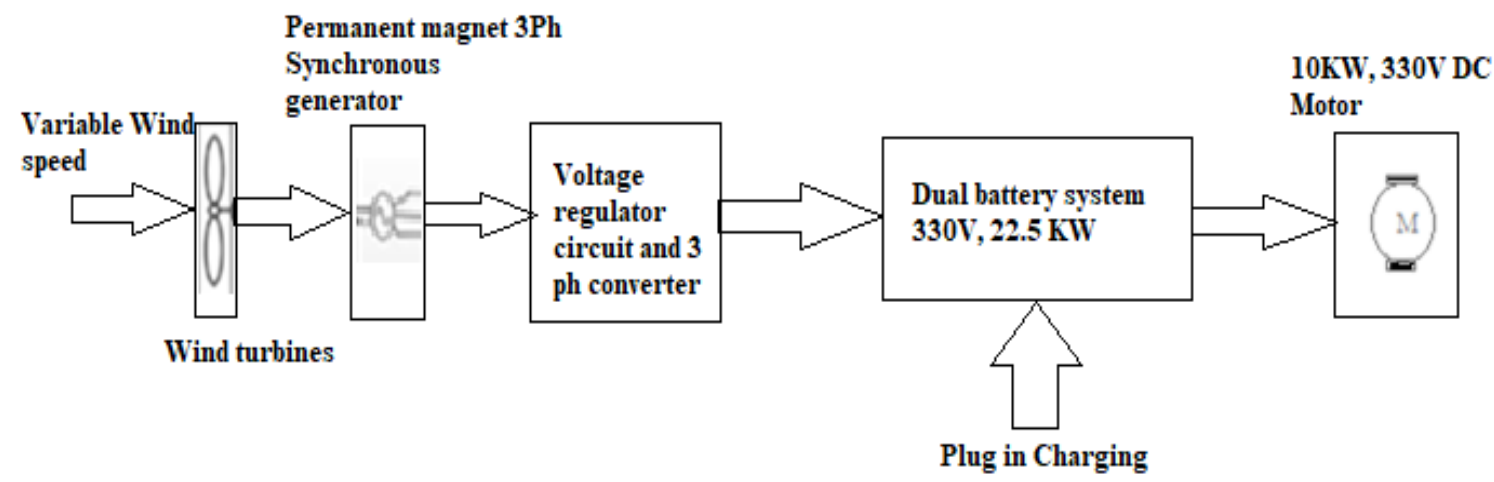

Fig 1. Block diagram of an Electric Vehicle with Wind powered dual batteries

Since this is a hybrid operation. Hybrid wind powered Electric Vehicles require high energy density energy storage system (ESS) for Electric Vehicle (EV) mode range and high-power density (ESS) for hybrid operation. The use of bidirectional DC-DC converter facilitates the use of multiple energy storage. The flexible DC-link voltages can increase the system efficiency and reduce component sizing. Figure 1 shows the block diagram. A motor control circuit can be used to control the motor which will provide Regenerative Braking. Simple Power diodes can be used for designing the converter circuit. The cut-in velocity of the turbines is $5 \mathrm{~m} / \mathrm{s}$.

2.2. Design and Modelling: An Electric car is considered with wind turbines set in parallel with the flow of air. This set up will not create any additional thrust at the direction of propulsion. The air flow and power extraction can be explained by two basic equations:

The air flow through the vehicle is given by, [2]

$\mathrm{Q}=\mathrm{C}_{\mathrm{v}} \mathrm{A} \mathrm{v}$

Where, $\mathrm{Q}=$ flow rate in cubic meter per second

$\mathrm{C}_{\mathrm{v}}=$ opening effectiveness

$\mathrm{A}=$ area in sq. Meters

$\mathrm{v}=$ velocity of air in $\mathrm{m} / \mathrm{s}$

This equation (1) will determine the amount of air flow through the vehicle inlet area.

Output power from a wind turbine is given by [4],

$\mathrm{P}_{\mathrm{T}}=0.5 \mathrm{C}_{\mathrm{P}} \rho \mathrm{Q} \mathrm{v}^{2}$

Where, $\mathrm{P}_{\mathrm{T}}=$ Power output from the turbine in watt.

$\mathrm{Cp}=$ Power co-efficient (Assuming, $\mathrm{Cp}=0.4$ for the design) [4]

$\rho=$ air density; $1.225 \mathrm{~kg} / \mathrm{m} 3$.

$\mathrm{Q}=$ air flow in $\mathrm{m} 3 / \mathrm{s}$.

$\mathrm{v}=$ air velocity in $\mathrm{m} / \mathrm{s}$. 

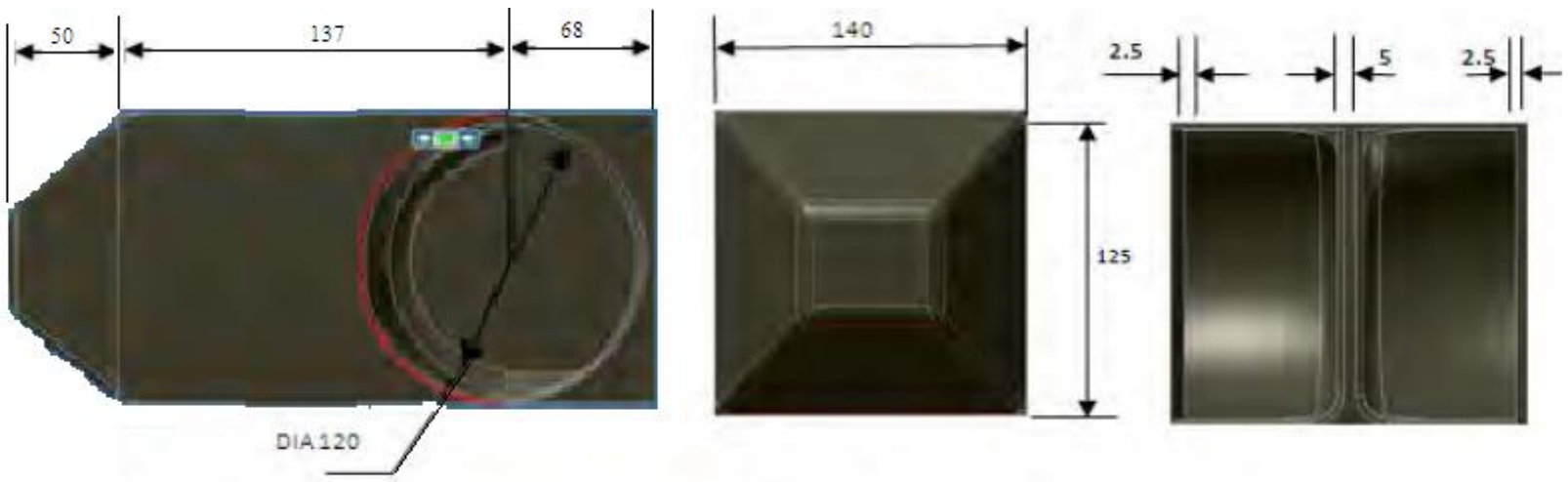

Fig. 2. Isometric views of the model. The diameter of the turbine is $120 \mathrm{~cm}$ which is placed at the rear side of the vehicle. The length of the vehicle is $255 \mathrm{~cm}$. All dimensions in the diagram are in centimetres.

Due to the presence of boundary layers and vortex shedding, air cannot go to rear side of the conventional vehicle. If a high-pressure and a low-pressure region can be connected via a neutral zone, then air can flow in between these pressure regions. This design allows the air to flow in this manner. The detail designs are shown in the fig.2.

Area of outlet $=65 * 125=8125 \mathrm{~cm} 2$

Area of inlet $=\mathrm{A}=\pi \mathrm{r}^{2}=3.1416 \times 60^{2}=11309.76 \mathrm{~cm}^{2}$

Ratio of outlet area to inlet area is 0.8 .

The research says the most generally utilized motors are the induction motors and the PM brushless motors. Induction motors are the savviest among the motors thought about. Taking efficiency into account, the most effective motors are the PM BLDC motors. DC motors have a standout among the most developed innovations as a great deal of research has been done on them throughout the years. The IMs and the SRMs are solid advancements and need minimum measure of upkeep. In this paper, a $330 \mathrm{~V}, 10 \mathrm{KW}$ DC motor is used. We can make use of 3 Phase AC motors like Induction motors, Synchronous reluctance motors, and permanent magnet synchronous reluctance motor (Three phase inverter can be used to convert DC to AC). The vehicle has to move at a velocity of $54 \mathrm{~km} / \mathrm{h}$ i.e., $15 \mathrm{~m} / \mathrm{s}$. The design of the electric vehicle is shown here with all dimensions. The wind turbines are set in such a way that the axial thrusts on the turbines are $180^{\circ}$ apart, which results in the cancellation of two thrusts. By this way, the symmetrical positioning of the turbines will create zero additional drag component over the vehicle. This arrangement of the wind turbines may facilitate charging of the vehicle in a parking place when the wind velocity is more than cut in speed. This arrangement of the wind turbine facilitates the roof top solar panels which can aid the recharging of the vehicle, both in motion and parked position.

2.3. Wind turbine: The features of the wind turbine chosen for power generation are stated as below [5] -

$>$ Two blades (Low solidity)

$>$ Horizontal axis.

$>$ Lift type

$>$ High lift to drag ratio with efficiency ranging from 0.4 to 0.45 . High tip speed ratio $\left(\lambda=\omega \mathrm{R} / \mathrm{v}_{\mathrm{w}}\right)$ is needed. For our design, we choose $\lambda=6$. For this value of $\lambda$, the value of $\mathrm{Cp}$ can be assumed as 0.4 to 0.45 .
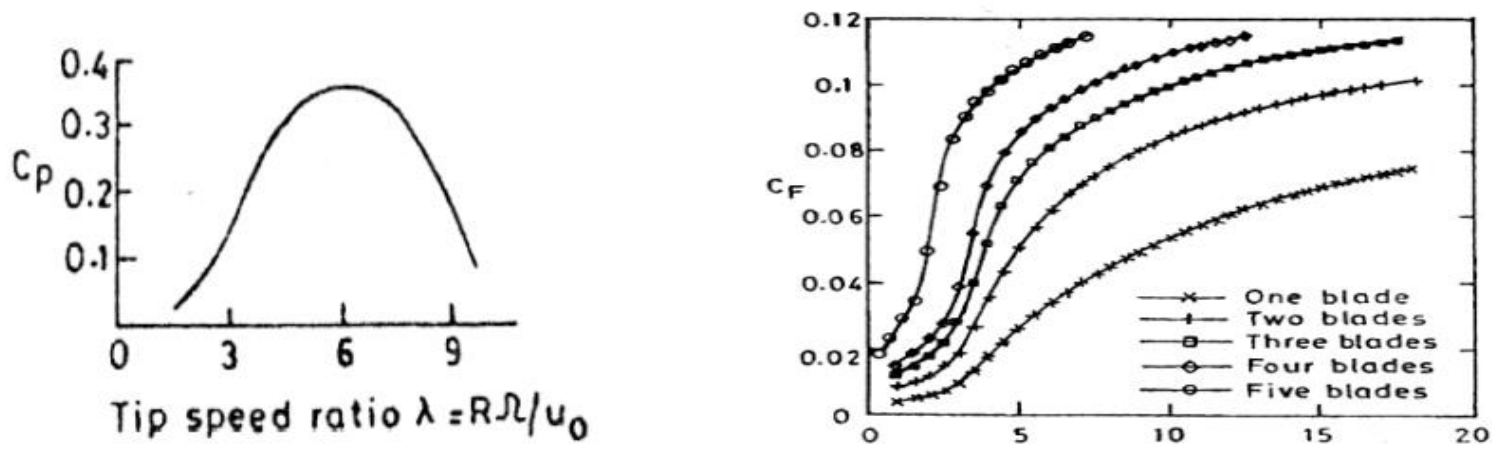

Fig.3. Power Coefficient and Axial Thrust Coefficient for HAWT [6]

We can see $\mathrm{Cp}=0.4$ and $\mathrm{CF}=0.054$ [6] from $\mathrm{Cp}-\lambda$ and $\mathrm{CF}-\lambda$ curve

Where, $\mathrm{CF}=$ axial thrust co-efficient.

So, $\mathrm{Cp} / \mathrm{CF} \approx 7.4$ 


\section{International Advanced Research Journal in Science, Engineering and Technology}

Vol. 8, Issue 6, June 2021

DOI: $10.17148 /$ IARJSET.2021.86113

This implies that power generated by a turbine is greater than the thrust acting on blades as an aerofoil section has high list to drag ratio. But the turbines are placed in parallel to the flow rather than perpendicular to the flow.

2.4. Generator: A Permanent magnet A.C. generator with 3- $\Phi$ windings with 8 no. of poles can be used.

$\lambda=6=\frac{\omega \mathrm{R}}{V w} ; \quad \omega=\frac{6 \mathrm{~V} w}{\mathrm{R}}=\frac{6 \times 15}{0.6}=150 \mathrm{rad} / \mathrm{s} ;$

R.P.M, $N=\frac{60 \times 150}{2 \pi}=1433.12 \mathrm{rpm}$;

A gear box can be used if needed. It is not necessary for this case.

We shall use three phase A.C. to D.C. converter to charge the batteries. The $60 \mathrm{~V}$ constant voltage is given by Cúk converter. In ćuk converter, the main energy-storage component is the capacitor. By variation of the speed of the vehicle or rpm of the turbine, the current of current will vary keeping the voltage constant.

2.5. Dual Battery System: Two batteries are used in the system. One battery A is "charge depleting" type with high energy density and the other battery B is charge enhancing type with high power density. The specification of battery A HE-602040 and battery B UHP-341450 are shown in the tables 1 and 2. Figure 4 shows the block diagram of dual battery system using converter.

The battery A can be pack of 93 number of 3.6V, 60 Ah HE-602040 batteries with high energy density with charge depleting strategy. This pack can provide $20 \mathrm{KWh}$. The battery B can be pack of 93 number of 3.6V, 7.5 Ah UHP341450 batteries pack with high power density is used with charge sustaining strategy. This pack can provide $2.5 \mathrm{KWh}$ [17]. 8KW bidirectional converter is used as dc link. For the battery B, the highest and lowest desired States of Charge (SOC) are set to 0.7 and 0.6 respectively. For the battery A, the highest and lowest desired SOC are set to 1.0 and 0.1 respectively. The initial SOC is set to be 1.0 for both EV and HEV batteries.

Table.1. Battery A Specification of HE-602040 (one battery)

\begin{tabular}{|l|l|}
\hline Parameter & Value \\
\hline Nominal Voltage & $3.6 \mathrm{~V}$ \\
\hline Nominal Capacity & $60 \mathrm{Ah}$ \\
\hline Weight & $1500 \mathrm{~g}$ \\
\hline Specific Energy & $144 \mathrm{Wh} / \mathrm{kg}$ \\
\hline Energy Density & $374 \mathrm{Wh} / \mathrm{l}$ \\
\hline Specific Power & $1800 \mathrm{~W} / \mathrm{Kg}$ \\
\hline Power Density & $4680 \mathrm{~W} / \mathrm{l}$ \\
\hline $\begin{array}{l}\text { Max.Discharge } \\
\text { Current }\end{array}$ & $120 \mathrm{~A}$ \\
\hline
\end{tabular}

Table.2. Battery B Specification of UHP-341450 (one battery)

\begin{tabular}{|l|l|}
\hline Parameter & Value \\
\hline Nominal Voltage & $3.6 \mathrm{~V}$ \\
\hline Nominal Capacity & $7.5 \mathrm{Ah}$ \\
\hline Weight & $320 \mathrm{~g}$ \\
\hline Specific Energy & $84 \mathrm{Wh} / \mathrm{kg}$ \\
\hline Energy Density & $211 \mathrm{Wh} / \mathrm{l}$ \\
\hline Specific Power & $9370 \mathrm{~W} / \mathrm{Kg}$ \\
\hline Power Density & $23470 \mathrm{~W} / \mathrm{l}$ \\
\hline $\begin{array}{l}\text { Max.Discharge } \\
\text { Current }\end{array}$ & $75 \mathrm{~A}$ \\
\hline
\end{tabular}




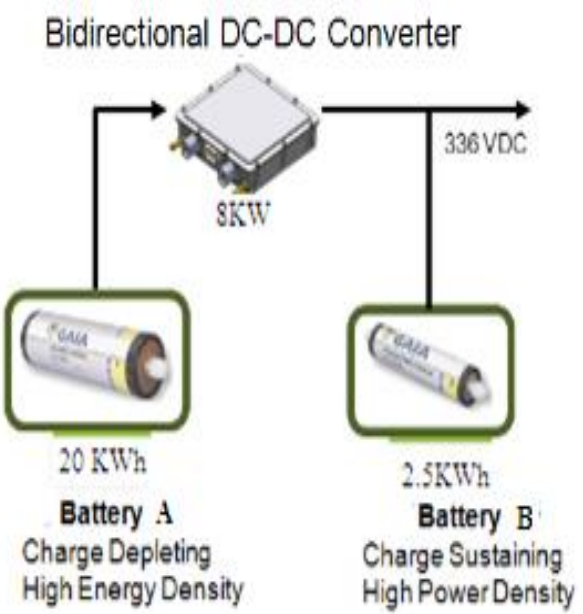

Fig.4. Dual battery system with DC converter

\subsection{Calculation:}

Using equation (1) we can calculate the amount of air flow, $\mathrm{Q}=\mathrm{C}_{\mathrm{v}} \mathrm{A} \mathrm{v}=0.27 \times 0.8 \times 1.1309 \times 15 \times 2=7.32 \mathrm{~m}^{3} / \mathrm{s}$

Here, $\mathrm{A}=\pi \mathrm{r}^{2}=3.1416 \times 0.6^{2}=1.1309 \mathrm{~m}^{2}$

$\mathrm{v}=54 \mathrm{kmph}=15 \mathrm{~m} / \mathrm{s}$

Here multiplier of $\mathrm{C}_{\mathrm{v}}$ is 8 (ratio of outlet area to inlet area).

$\mathrm{C}_{\mathrm{V}}$ is chosen as 0.27 as it is a skewed flow [3].

Power, $\mathrm{P} w=\frac{1}{2} \rho \mathrm{Q} \mathrm{v}^{2}=\frac{1}{2} \times 1.225 \times 7.32 \times 15^{2}=1008.79 \mathrm{~W}$

Assuming, $\mathrm{Cp}=0.4$

Then we have, $\mathrm{P}_{\mathrm{T}}=1008.79 \times 0.4=403.515 \mathrm{~W} \approx 400 \mathrm{~W}$

Power produced by each turbine is $200 \mathrm{~W}$.

\section{RESULTS AND DISCUSSION}

\subsection{Result with Wind turbines}

Each turbine produces a power of $200 \mathrm{~W}$ when the vehicle is moving at a speed of $15 \mathrm{~m} / \mathrm{s}$ or $54 \mathrm{Kmph}$. So, total power supplied by the turbines $\mathrm{P}_{\mathrm{T}}$ is $400 \mathrm{~W}$. This power $\mathrm{P}_{\mathrm{T}}$ will be fed back to the battery when it is moving at a constant velocity of $15 \mathrm{~m} / \mathrm{s}$. It is observed that mileage is increased by more than $10 \%$. The vehicle will spend some energy to overcome aerodynamic drag. A fraction of this energy is captured by turbines.

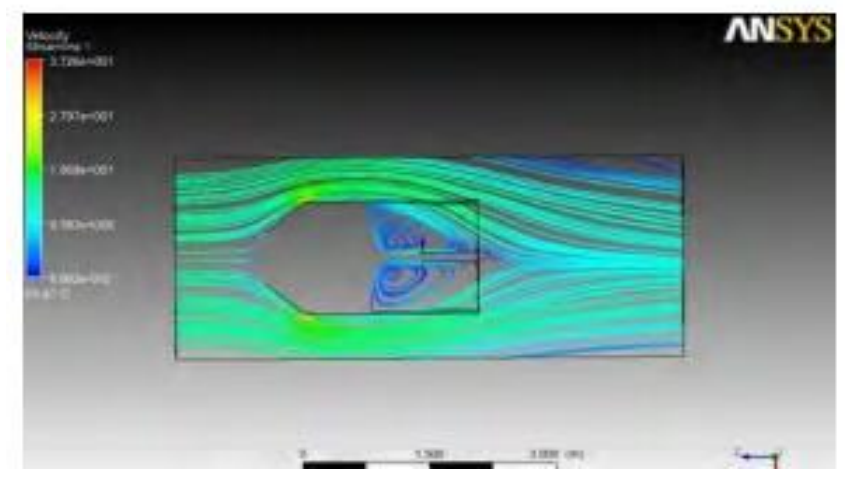

Fig.5. Streamline of flow over the vehicle.

The flow pattern over vehicle is simulated by ANSYS CFX. It is observed that the vortexes on the design are reduced. Also, as the streamlines are leaving the vehicle, an additional propulsive thrust can be obtained. [11] 


\section{International Advanced Research Journal in Science, Engineering and Technology}

Vol. 8, Issue 6, June 2021

DOI: $10.17148 /$ IARJSET.2021.86113

Table 3. Simulation results for pressure and forces

\begin{tabular}{|l|l|l|l|c|}
\hline \multirow{2}{*}{$\begin{array}{l}\text { Comparison } \\
\text { Parameters }\end{array}$} & \multicolumn{2}{|l|}{ Conventional Design } & \multicolumn{2}{l|}{$\begin{array}{l}\text { Modified Design with ducts } \\
\text { for turbine }\end{array}$} \\
\cline { 2 - 5 } & Inlet & Outlet & Inlet & Outlet \\
\hline Pressure $(\mathrm{Pa})$ & 2.28086 & -1.24285 & 2.28652 & 0.24047 \\
\hline Force $($ Drag $)(\mathrm{N})$ & 45.9041 & 6.4954 & 15.5202 & 11.5141 \\
\hline
\end{tabular}

Table 3 shows the plane force and pressure over the Conventional design and modified design with ducts. The outlet pressure is increased for the modified design which indicates a reduction in form drag.

\subsection{Result with Dual battery system}

The battery A charge depleting type with high energy density provides the average power while the battery B charge enhancing type with high power density provides the extra power required. Battery A provides most of the energy. Better performance and higher overall efficiency are achieved by this system. [17] The dual battery system is also more cost effective and allows the best utilization of battery technologies for both high power density and high energy density. Furthermore, the vehicle performance and handling are not compromised as the battery is operating in low SOC after charge depletion operation mode. The battery energy capacity is fully utilized. The battery system life cycle for the charge depletion battery is based on the charge cycles, while the charge enhancing battery life cycle is for power cycling at higher SOC band of operation.

\section{CONCLUSION}

In this paper, we studied a model of a hybrid wind-powered electric vehicle which uses wind energy to charge batteries along with the usage of multiple energy storage. We have reviewed the research on the vehicle model with the placement of the turbines in the vehicle and also the research on facilitating multiple energy storage. As per preceding research and findings, it implies that the drag would be induced due to the use of turbines, but the wind energy captured by turbines with reduced vortex shedding at the rear side will even out the effect and also powers the battery. Electric vehicle range is increased by the use of wind turbines and dual battery system. The battery energy capacity can be fully utilized. Mileage can be increased. We believe elaborate analysis and research is required in which we expect to continue in the future so as to have high-range electric vehicles powered by renewable energy sources effectively.

\section{REFERENCES}

1. Thomas D. Gillespie, "Fundamentals of Vehicle Dynamics", Society of Automotive Inc.

2. Terry S. Boutet," Controlling Air Movements- A Manual for Builders and Architects", McGraw - Hill Book Company.

3. Victor Olgyay, "Design with climate", Princeton University Press, 1963, p.104

4. Godfrey Boyle, "Renewable Energy- Power for a sustainable future", Oxford University Press.

5. Dr. Amalesh Chandra Mandal, Dr. Md. Quamrul Islam, "Aerodynamics and Design of Wind Turbines", Published by BUET.

6. G.N.Tewari, A.K. Bansal, "Renewable Energy Resources”, Narosa Publishing House.

7. Martin O.L. Hansen, “Aerodynamics of Wind Turbines", Earthscan, London.

8. Bent Sorensen, "Renewable Energy" Academic Press, USA.

9. Mukund R. Patel, "Wind and Solar Power Systems" CRC Press, USA.

10. John D. Anderson, "Fundamentals of Aerodynamics", McGraw Hill Book Company.

11. S.M. Ferdous, Walid Bin Khaled, Benozir Ahmed, Sayedus Salehin, Enaiyat Ghani Ovy Electric Vehicle with Charging Facility in Motion using Wind Energy - World Renewable energy congress 2011- 8-13 May 2011.

12. S.K. Mazumder, C. Tan, and K. Acharya, Design of a radio frequency controlled parallel dc-dc all-SiC converter, IEEE Power Electronics Specialists Conference, June 2007, pp. 2833-2839.

13. Mazumder and S. Pradhan, Efficient and robust power management of reduced cost distributed power electronics for fuel-cell power system, ASME Journal of Fuel Cell Science and Technology, 2008.

14. Aymeric Rousseau, Neeraj Shidore, Richard Carlson, VRLA automotive batteries for stop \& go and dual battery systems, Journal of Power Sources, Volume 144, Issue 2, 15 June 2005, Pages 411-417

15. J. G. Kassakian, Automotive Electrical Systems -the Power Electronics Market of the Future, IEEE APEC 2000.

16. J. M. Miller and A. R. Gale, Hybrid Electric Vehicle Success Will Depend on Low Cost, Efficient Power Electronics Systems, PCIM, vol. 23, no. 11, November 1997.

17. Farzad Ahmadkhanlou, Abas Goodarzi, and Don Kang Plug-In Hybrid Electric Vehicle with Dual Battery System - The 25th World Battery, Hybrid and Fuel Cell Electric Vehicle Symposium \& Exhibition Nov. 5-9, 2010.

18. T.Vignesh, S.Sathish Kumar, D.Silambarasan, Design of Hybrid Electric Vehicles Using Solar and Wind energy with Arduino Processor, Interanational Journal of Advanced Research in Electrical, Electronics and Instrumentation Vol 6, Issue 3, March 2017.

19. Bhagyashree R. Wadhai, Asmita S. Nagrare, Manjushree D. Kambl, Trupti J. Durge, Mr. Vivek S.Narnaware, SOLAR AND WIND POWERED HYBRID VEHICLE PROTOTYPE, April 2016 IJSDR | Volume 1, Issue 4.

20. Steven Keeping Use Specialized Power Converters to Bridge the Dual 12 V to 48 V Gap in Automotive Systems, Contributed by Digi-Key's North American Editors,2020-06-23. 